\title{
Changes in corneal endothelium cell characteristics after cataract surgery with and without use of viscoelastic substances during intraocular lens implantation
}

\author{
This article was published in the following Dove Press journal: \\ Clinical Ophthalmology \\ 6 November 2015 \\ Number of times this article has been viewed
}

Purpose: To evaluate whether the use of balanced salt solution (BSS) or an ophthalmic viscoelastic device (OVD) during hydrophilic acrylic intraocular lens (IOL) implantation variously impacts corneal endothelial cell characteristics in eyes undergoing uneventful phacoemulsifications.

Methods: Prospective nonrandomized observational clinical trial. Patients were assigned either to the BSS plus ${ }^{\circledR}$ or to the OVD Z-Celcoat ${ }^{\mathrm{TM}}$ group depending on the substance used during IOL implantation. Corneal endothelium cell characteristics were obtained before, 1 week, and 6 weeks after surgery. Intraoperative parameters (eg, surgery time, phacoemulsification energy) were recorded.

Results: Ninety-seven eyes were assigned to the BSS plus and 86 eyes to the Z-Celcoat group. Preoperative corneal endothelium cell density (ECD) and endothelium cell size were $2,506 \pm 310$ cells $/ \mathrm{mm}^{2} / 2,433 \pm 261$ cells $/ \mathrm{mm}^{2}$ and $406 \pm 47 \mu \mathrm{m}^{2} / 416 \pm 50 \mu \mathrm{m}^{2}(P=0.107 / P=0.09)$. After 1 and 6 weeks, ECD decreased and endothelium cell size increased significantly in both groups (each $P<0.001$ ) without significant differences between both groups (each $P>0.05$ ). Irrigation-aspiration suction time $(30.3 \pm 16.6$ versus $36.3 \pm 14.5$ seconds) and overall surgical time ( $7.2 \pm 1.2$ versus $8.0 \pm 1.4$ minutes) were significantly longer in the OVD Z-Celcoat group (each $P<0.001$ ). No complications or serious side effects occurred.

Conclusion: Implantation of a hydrophilic acrylic IOL under BSS infusion seems to be a useful and faster alternative in experienced hands without generating higher ECD loss rates.

Keywords: phacoemulsification, ophthalmic viscoelastic device, endothelial cell density, IOL

\section{Introduction}

To date, cataract surgery is the most frequently performed surgical intervention in developed countries, ${ }^{1}$ and within the last decades, tremendous improvements have been made with regard to surgical techniques as well as applications of additive tools among others. ${ }^{2}$ This ensures a less traumatic surgical maneuver and significantly decreases complication rates.

In this respect, the use of ophthalmic viscoelastic devices (OVD) during the procedure has emerged into the focus of scientific and clinical interest. ${ }^{3}$ OVDs can be useful to maintain stability of the anterior chamber (AC), for instance, during capsulorhexis to ensure completion and creation of an ideal size. OVDs enlarge and stabilize pupil size in small pupils or intraoperative floppy iris syndrome and help to avoid posterior capsule rupture. ${ }^{3}$ OVDs can furthermore be of benefit in eyes with
Correspondence: Stephan D Schulze Department of Ophthalmology, Philipps University of Marburg, Baldingerstraße,

D-35043 Marburg, Germany

Tel $+49642 I 5862600$

Fax +49 642I 5865678

Email schulzes@med.uni-marburg.de 
high positive vitreous pressure (vis-a-tergo), for example, in heavily overweight patients with pulmonary diseases, proptotic globes, and tight orbits, ${ }^{3}$ and may diminish large intraocular pressure (IOP) fluctuations during surgery. ${ }^{4}$ These fluctuations are likely a predisposing risk factor for expulsive hemorrhages, and OVDs can help to maintain AC depths, tamponade further bleeding, and allow the surgeon to seal the globe even in this scenario. ${ }^{3,4}$ If an intraoperative posterior capsular defect occurs, OVDs can facilitate to push vitreous backward and assist to implant the intraocular lens (IOL) into the ciliary sulcus. ${ }^{4}$

One of the main aspects in OVD use remains the protection of intraocular structures and in particular of corneal endothelium cells (CECs) during cataract surgery though. ${ }^{5}$ An OVD is believed to protect the CECs during the phacoemulsification maneuver due to suppression of free radical formation, ${ }^{6}$ which is of notable importance in eyes with Fuchs endothelial dystrophy. ${ }^{7}$ It also plays an immanent role in avoiding CEC contact with lens, iris, surgical instruments, and the IOL to be inserted during and after the implantation process,${ }^{8}$ all of which can lead to a sustained CEC loss. ${ }^{9,10}$ Generally speaking, the use of OVDs during cataract surgery can make the procedure easier and safer.

In contrast, it can also cause postoperative IOP elevations, if not completely removed. ${ }^{3,8,11}$ If there is no fluid space around the tip during phacoemulsification, wound burns can occur due to temperature increase. ${ }^{3}$ Furthermore, if OVDs remain within the corneal incisions, self-sealing might be hampered. ${ }^{3}$ The intraoperative use of OVDs for IOL implantation increases overall operation time because extra time is needed to insert and completely remove the injected OVD. ${ }^{3}$ Aspiration times can differ according to the specific OVDs used. ${ }^{3,11,12}$ Besides a prolonged operation time, which per se increases overall operation risks and complications, OVD removal can immediately affect safety issues. Oftentimes, it is not easy to completely remove the OVD from the ciliary sulcus and from behind the IOL, in the worst-case scenario, leading to a capsular distension syndrome. ${ }^{13}$ An increased irrigation-aspiration time ${ }^{14}$ and the irrigation solution used ${ }^{15}$ might also be responsible for CEC loss due to the aspiration trauma. These data demonstrate that the use of OVDs can have side effects and may cause CEC loss as well. Finally, the use of OVDs during toric IOL implantation can be a disadvantage due to an increased rotation tendency, if not completely removed. Furthermore, a new bioanalogic IOL is available (WIOL-CF ${ }^{\circledR}$; Medicem International, Zug, Switzerland; http://www.wiols.com/) to be implanted without OVD use.
The question whether the use of OVDs during IOL implantation to protect the CECs is beneficial or not is of interest because theoretically both balanced salt solution (BSS) and air can be used during this stage. The disadvantage is that both of them can easily escape leading to a collapse of the AC. ${ }^{8}$ This may cause direct CEC contact with the IOL or other structures. However, the introduction of self-sealing small-incision cataract surgery with foldable hydrophilic IOLs may negate the need for OVDs during implantation reducing time and costs of the procedure. ${ }^{8}$

Thus, the aim of this study was to evaluate whether the use of BSS plus ${ }^{\circledR}$ (Alcon Laboratories, Inc., Fort Worth, TX, USA) or Z-Celcoat ${ }^{\mathrm{TM}}$ (Carl Zeiss Meditec AG, Jena, Germany) during a hydrophilic IOL implantation variously impact $\mathrm{CEC}$ characteristics in routine cataract removal procedures.

\section{Methods}

This prospective clinical study was performed in accordance with the Helsinki Declaration of 1975 (1983 revision). The institutional review board of the Chamber of Physicians of the State of Bremen approved the protocol before study initiation. One hundred and twenty-seven consecutive patients (183 eyes) who were scheduled for a routine phacoemulsification and IOL implantation procedure between June 2010 and January 2012 were enrolled in our study after written consent was obtained from each subject following an explicit explanation of the purpose and potential side effects of each procedure. All patients participating between June 2010 and February 2011 were assigned to be BSS plus group, and all attendees between March 2011 and January 2012 were allotted into the Z-Celcoat group. A randomization protocol was not applied in order not to disrupt the routine workflow in a very busy high-volume surgical ambulatory center.

All surgeries were performed by one single surgeon (SB) in an outpatient setting. Phacoemulsification was conducted if a clinically observed senile opacification of the lens was seen at slit lamp examination, and removal of the lens was expected to increase visual acuity as tested with laser interferometer prior to surgery. The cataract surgery was performed as follows: temporal clear cornea incision of $2.6 \times 2.5 \mathrm{~mm}$, two side-ports, injection of OVD into the AC, anterior capsulorhexis under OVD Z-Celcoat, hydrodissection, phacoemulsification with the Pentasys $2^{\circledR}$ device (Fritz Ruck GmbH, Eschweiler, Germany), and IOL implantation (CTAsphina $^{\circledR} 409 \mathrm{M}$ or CT-Asphina 409MV; Carl Zeiss Meditec AG) into the bag using a single-use injector. According to the manufacturer, the CT-Asphina IOL is made of hydrophilic 
material $(25 \%)$ with a hydrophobic surface coating. This lens can be compressed for an implantation incision size of $1.8 \mathrm{~mm}$ without damage. Patients were assigned either to the BSS plus group if BSS was used during IOL implantation or to the Z-Celcoat group if the latter was applied. Z-Celcoat is a dispersive viscoelastic substance containing hydroxypropylmethylcellulose. In particular, the AC was maintained in the first group by holding the irrigation tip with BSS plus infusion through the side-port with the left hand while injecting the IOL with the one-hand injector in the right hand. In the second group, the OVD (Z-Celcoat) was injected into the $\mathrm{AC}$ and into the cartridge and the eye stabilized with a spatula during IOL implantation.

Exclusion criteria were pathologies of the cornea, such as cornea guttata or corneal scars, inflammatory diseases, such as iritis or retinitis, exudative age-related macular degeneration, proliferative diabetic vitreoretinopathy, retinal ischemic diseases, secondary glaucoma or insufficiently treated open-angle glaucoma, and any ophthalmic surgery in the past.

Best-corrected visual acuity (BCVA) was determined by performing subjective refraction and advising the patient afterward to read standard decimal visual acuity charts at $6 \mathrm{~m}$ distance. BCVA was then recorded in decimal notation. IOP was evaluated using routine Goldman applanation tonometry. Thereafter, the ocular surface was anesthesized and stained with Thilorbin ${ }^{\circledR}$ eye drops (Omnivision $\mathrm{GmbH}$, Puchheim, Germany), and IOP was read from the measuring wheel. Corneal endothelium cell density (ECD) and corneal endothelium cell size (ECS) were measured automatically with the endothelial specular microscope Tomey EM-3000 and its integrated software (Tomey Inc., Erlangen, Germany). Intraoperative parameters such as phacoemulsification time and energy, phacoemulsification suction time, as well as irrigation-aspiration suction time were directly taken from the phacoemulsification device.

\section{Statistical analysis}

To evaluate the overall distributions of sex and group size, the binomial distribution test was performed. To compare the baseline, intraoperative, and postsurgical parameters between both groups, the Mann-Whitney $U$-test was conducted. To test the differences within each group in the postsurgical course, a $t$-test was conducted. For all statistical tests, a significance level of $1-\alpha=0.95$ was assumed.

Using a multivariate regression analysis, it was investigated which of the variables (age, sex, operation time, phacoemulsification time, phacoemulsification energy, phacoemulsification suction time, and irrigation-aspiration time) significantly affects the effect of BSS plus or Z-Celcoat on BCVA, IOP, ECD, and ECS (development). Such a significant effect could not be shown for any of these dependent variables. This in turn justifies the direct comparison of all parameters evaluated between both groups using the MannWhitney $U$-test.

\section{Results}

Overall, 183 eyes from 127 patients were included into this series, thereof 92 right eyes and 91 left eyes (50\% each). Mean patient age was $73 \pm 6.3$ years (mean value \pm standard deviation). Forty-five patients (35\%) were male and 82 participants $(65 \%)$ female $(P<0.001)$. Surgery was performed in one eye in 72 patients $(57 \%)$ and in both eyes in 55 attendees (43\%). Two patients (4\%) who received bilateral surgery had one eye assigned into the BSS plus group and the fellow eye into the Z-Celcoat group. There were no differences in the number of diabetic patients or in tamsulosin intake between both groups.

Overall BCVA at baseline was $0.43 \pm 0.17$, and IOP was measured to be $15.7 \pm 2.7 \mathrm{mmHg}$. ECD and ECS were detected with $2,472 \pm 290$ cells $/ \mathrm{mm}^{2}$ and $411 \pm 54 \mu \mathrm{m}^{2}$, respectively. The baseline characteristics of the BSS plus and Z-Celcoat groups are depicted in Table 1.

Table I Baseline characteristics of patients assigned to the BSS plus ${ }^{\circledR}$ or Z-Celcoat ${ }^{\mathrm{TM}}$ group

\begin{tabular}{|c|c|c|c|}
\hline & BSS plus ${ }^{\circledR}$ group & Z-Celcoat ${ }^{\mathrm{TM}}$ group & $P$-value \\
\hline Number of eyes & $97(53 \%)$ & $86(47 \%)$ & 0.460 \\
\hline Age (years) & $73 \pm 6.0$ & $73 \pm 6.5$ & 0.435 \\
\hline Sex (male/female) & $42 / 55(43 \% / 57 \%)$ & $22 / 64(26 \% / 74 \%)$ & $0.012^{\mathrm{a}}$ \\
\hline Number of diabetic patients & $4(4.1 \%)$ & 7 (8. I\%) & 0.273 \\
\hline Patients taking tamsulosine & $8(8.2 \%)$ & $6(7 \%)$ & 0.933 \\
\hline Corneal endothelium cell density (ECD) (cells $\left./ \mathrm{mm}^{2}\right)$ & $2,506 \pm 310$ & $2,433 \pm 261$ & 0.107 \\
\hline Average size of corneal endothelium cell $\left(\mu \mathrm{m}^{2}\right)(\mathrm{ECS})$ & $406 \pm 57$ & $416 \pm 50$ & 0.097 \\
\hline Anterior chamber depth $(\mathrm{ACD})(\mathrm{mm})$ & $3.3 \pm 0.43$ & $3.24 \pm 0.43$ & 0.243 \\
\hline
\end{tabular}

Notes: aSignificant differences between both groups. Data are represented as mean \pm standard deviation unless otherwise stated. Abbreviations: BSS, balanced salt solution; ECS, endothelium cell size. 
In all 183 cases, an uneventful phacoemulsification with IOL implantation into the capsular bag was performed. Overall mean surgical time was $7.6 \pm 1.4$ minutes, mean phacoemulsification time was calculated to be $37.1 \pm 14.4$ seconds, phacoemulsification energy was read to be $138.5 \pm 90.8 \mathrm{~J}$, phacoemulsification suction time was $43.2 \pm 17.1$ seconds, and irrigation-aspiration suction time was $33.1 \pm 15.9$ seconds. Comparative intraoperative parameters for the BSS plus and Z-Celcoat groups are shown in Table 2. One day after surgery, control examinations of eyes operated revealed an overall IOP of $15.7 \pm 2.4 \mathrm{mmHg}$. Postsurgical evaluation after 1 week displayed an overall gain in BCVA to $0.75 \pm 0.16(P<0.001$, in comparison to baseline), an IOP of $15.4 \pm 2.1 \mathrm{mmHg}(P=0.220$, in comparison to baseline), a reduction of ECD to $2,324 \pm 350$ cells $/ \mathrm{mm}^{2}$ $(P<0.001$, in comparison to baseline), and an increase in ECS upon $442 \pm 82 \mu \mathrm{m}^{2}(P<0.001$, in comparison to baseline). Six weeks after the cataract removal procedure, BCVA increased further to $0.83 \pm 0.16(P<0.001$, in comparison to baseline) and IOP was stable with $15.4 \pm 2.0 \mathrm{mmHg}(P=0.248$, in comparison to baseline). Overall ECD decreased and ECS increased further to $2,294 \pm 362$ cells $/ \mathrm{mm}^{2}(P<0.001$, in comparison to baseline) and $449 \pm 87 \mu \mathrm{m}^{2}(P<0.001$, in comparison to baseline), respectively. Separated postoperative results for the BSS plus and Z-Celcoat groups are demonstrated in Table 3.

\section{Discussion}

The problem whether to use BSS or an OVD for IOL implantation during cataract surgery to ensure the best protection of the corneal endothelium is of interest for each cataract surgeon. ${ }^{16}$ As mentioned in the introduction, both approaches have their pros and cons. On the one hand, OVDs can make IOL implantation safer by maintaining the AC and diminishing the contact of the CECs with intraocular structures, instruments, or the IOL. ${ }^{3,8}$ OVDs might furthermore reduce mechanical stress and wrinkling of the cornea when the injector is pushed through the tunnel and thus protect the CECs. On the other hand, additional irrigation-aspiration time is needed to completely remove the OVD to avoid postoperative IOL spikes ${ }^{3,8,11}$ and the removal procedure per se can be difficult in some cases. ${ }^{11,16}$ Both aspects extend overall procedure time and increase intraocular manipulation and fluid flow as well as aspiration time, both of which might directly or indirectly affect CEC characteristics. The composition of the irrigation fluid used might have an effect on CEC features as well. ${ }^{17,18}$

This study was conducted to evaluate the advantages and disadvantages of the two alternative techniques in a routine high-volume setting, where every second counts and an excellent outcome is anticipated by referring doctors. With respect to baseline characteristics, no differences were found between both groups with the exception that more female patients were assigned to the Z-Celcoat group. This aspect might be of marginal importance because no significant differences in ECD and ECS between both groups were obtainable at baseline (Table 1). Furthermore, a comparable sex distribution was also found in former studies. ${ }^{19}$

Several factors impact CEC characteristics during cataract surgery, including incision size, ${ }^{20}$ phacoemulsification technique, ${ }^{21,22}$ and thus formation of free radicals, ${ }^{6,18}$ hardness of the nucleus, ${ }^{23}$ and the amount of total ultrasonic energy ${ }^{24,25}$ among others. In this investigation, all surgeries were performed by one single surgeon. Thus, the incision size and phacoemulsification technique were equivalent for both groups. To exclude the variable effects of total operation time, phacoemulsification time, energy, and suction time as well as irrigation-aspiration suction time on the outcome of CEC characteristics (Table 2), a multivariate regression analysis was performed and no significant impact of these variables on CEC characteristics between both groups was detected ( $P$-values not shown). In fact, the comparison of postsurgical results between both groups herein solely describes the effect of either substance (BSS plus or Z-Celcoat) used during IOL implantation.

Comparing the intraoperative parameters between both groups, no significant differences with respect to

Table 2 Intraoperative parameters of patients assigned to the BSS plus ${ }^{\circledR}$ or Z-Celcoat ${ }^{\mathrm{TM}}$ group

\begin{tabular}{|c|c|c|c|}
\hline & BSS plus $^{\circledR}$ group & Z-Celcoat ${ }^{\mathrm{TM}}$ group & $P$-value \\
\hline Operation time (minutes) & $7.2 \pm 1.2$ & $8.0 \pm 1.4$ & $<0.00 I^{\mathrm{a}}$ \\
\hline Phacoemulsification time (seconds) & $37.0 \pm 16.3$ & $37.3 \pm 12.0$ & 0.574 \\
\hline Phacoemulsification energy $(\mathrm{J})$ & $136.0 \pm 104.3$ & $|4| .3 \pm 73 . \mid$ & 0.210 \\
\hline Phacoemulsification suction time (seconds) & $43.1 \pm 19.5$ & $43.3 \pm 14.1$ & 0.478 \\
\hline Irrigation-aspiration suction time (seconds) & $30.3 \pm 16.6$ & $36.3 \pm 14.5$ & $<0.00 \mathrm{I}^{\mathrm{a}}$ \\
\hline
\end{tabular}

Notes: aSignificant differences between both groups. Data are represented as mean \pm standard deviation.

Abbreviation: BSS, balanced salt solution. 
Table 3 Comparison of postsurgical results between patients assigned to the BSS plus ${ }^{\circledR}$ or Z-Celcoat ${ }^{\mathrm{TM}}$ group

\begin{tabular}{|c|c|c|c|}
\hline & BSS plus ${ }^{\circledR}$ group & Z-Celcoat $^{\mathrm{TM}}$ group & $P$-value \\
\hline \multicolumn{4}{|l|}{ BCVA } \\
\hline Baseline & $0.42 \pm 0.17$ & $0.44 \pm 0.18$ & 0.448 \\
\hline Week I & $0.77 \pm 0.17$ & $0.73 \pm 0.15$ & $0.010^{\mathrm{a}}$ \\
\hline Week 6 & $0.83 \pm 0.17$ & $0.83 \pm 0.14$ & 0.663 \\
\hline \multicolumn{4}{|l|}{$\triangle \mathrm{BCVA}$ ( $P$-value) } \\
\hline Baseline/week I & $0.36 \pm 0.18(<0.001)^{\mathrm{a}}$ & $0.29 \pm 0.22(<0.00 \mathrm{I})^{\mathrm{a}}$ & $0.009^{a}$ \\
\hline Baseline/week 6 & $0.4 I \pm 0.18(<0.00 I)^{\mathrm{a}}$ & $0.39 \pm 0.2 \mathrm{I}(<0.00 \mathrm{I})^{\mathrm{a}}$ & 0.398 \\
\hline \multicolumn{4}{|l|}{ IOP (mmHg) } \\
\hline Baseline & $15.5 \pm 2.8$ & $15.9 \pm 2.5$ & 0.206 \\
\hline Day I & $15.2 \pm 2.5$ & $16.4 \pm 2.1$ & $<0.00 \mathrm{I}^{\mathrm{a}}$ \\
\hline Week I & $15.0 \pm 2.2$ & $15.9 \pm 2.0$ & $0.00 I^{a}$ \\
\hline Week 6 & $15.0 \pm 2.1$ & $15.9 \pm 1.8$ & $0.00 I^{a}$ \\
\hline \multicolumn{4}{|c|}{$\Delta \mathrm{IOP}(\mathrm{mmHg})(P$-value $)$} \\
\hline Baseline/day I & $-0.3 \pm 3.3(0.331)$ & $0.49 \pm 2.9(0.117)$ & 0.107 \\
\hline Baseline/week I & $-0.5 \pm 3.0(0.077)$ & $0.0 \pm 2.6(0.832)$ & 0.119 \\
\hline Baseline/week 6 & $-0.5 \pm 3.0(0.116)$ & $0.0 \pm 2.7(0.97 I)$ & 0.217 \\
\hline \multicolumn{4}{|l|}{$\mathrm{ECD}\left(\right.$ cells $\left./ \mathrm{mm}^{2}\right)$} \\
\hline Baseline & $2,506 \pm 310$ & $2,433 \pm 261$ & 0.107 \\
\hline Week I & $2,348 \pm 347$ & $2,298 \pm 354$ & 0.407 \\
\hline Week 6 & $2,3|4 \pm 38|$ & $2,272 \pm 340$ & 0.361 \\
\hline \multicolumn{4}{|c|}{$\Delta \mathrm{ECD}\left(\right.$ cells $\left./ \mathrm{mm}^{2}\right) /(\%)(P$-value $)$} \\
\hline Baseline/week I & $-159 \pm 294 /(6.3)(<0.001)^{\mathrm{a}}$ & $-134 \pm 257 /(5.5)(<0.001)^{a}$ & 0.391 \\
\hline Baseline/week 6 & $-192 \pm 300 /(7.7)(<0.001)^{\mathrm{a}}$ & $-160 \pm 252 /(6.6)(<0.001)^{a}$ & $0.57 I$ \\
\hline \multicolumn{4}{|l|}{$\mathrm{ECS}\left(\mu \mathrm{m}^{2}\right)$} \\
\hline Baseline & $406 \pm 57$ & $416 \pm 50$ & 0.09 \\
\hline Week I & $437 \pm 81$ & $447 \pm 83$ & 0.409 \\
\hline Week 6 & $446 \pm 91$ & $452 \pm 83$ & 0.363 \\
\hline \multicolumn{4}{|c|}{$\Delta \mathrm{ECS}\left(\mu \mathrm{m}^{2}\right) /(\%)(P$-value $)$} \\
\hline Baseline/week I & $32 \pm 67 /(7.6)(<0.00 \mathrm{I})^{\mathrm{a}}$ & $3 \mathrm{I} \pm 60 /(7.5)(<0.00 \mathrm{I})^{\mathrm{a}}$ & 0.645 \\
\hline Baseline/week 6 & $4 \mathrm{I} \pm 74 /(9.9)(<0.00 \mathrm{I})^{\mathrm{a}}$ & $35 \pm 64 /(8.7)(<0.001)^{a}$ & 0.779 \\
\hline
\end{tabular}

Notes: Results and changes within each group are displayed in correspondent columns and comparisons between both groups are arranged in correspondent lines. aSignificant differences. Data are represented as mean \pm standard deviation.

Abbreviations: BSS, balanced salt solution; BCVA, best-corrected visual acuity; IOP, intraocular pressure; ECD, endothelium cell density; ECS, endothelium cell size.

phacoemulsification time, energy, and suction time were detectable (Table 2), which in turn demonstrates that lens characteristics did not differ between both groups. A presurgical evaluation of the cataracts to be removed in accordance with the Lens Opacities Classification System III ${ }^{26}$ might have emphasized this observation, but this system remains, at least in part, subjective. Using the exact intraoperative phacoemulsification parameters as analyzed herein should even be more objective in this respect.

With regard to CEC characteristics, the data presented herein show that there are no significant differences in overall ECD between both groups at baseline as well as after 1 and 6 weeks (Figure 1). In contrast, in the BSS plus and Z-Celcoat group, there was a significant CEC loss after 1 and 6 weeks without any significant difference between both groups (Table 3). Overall ECS did not differ significantly between both groups at any time either (Figure 2). ECS in the BSS plus and Z-Celcoat group increased significantly after $1 / 6$ weeks $\sim 7.6 \% / 9.9 \%$ and $7.5 \% / 8.7 \%$ (Table 3 ). These results demonstrate that there is a significant CEC loss and a consecutive ECS increase 1 and 6 weeks after an uneventful phacoemulsification irrespective of the fact which fluid/device was used for IOL implantation. This is an interesting observation because these results indicate that there is no additional benefit in the use of OVDs during IOL implantation at least in experienced hands using a single-hand injector (Figure 3) and a hydrophilic acrylic IOL. CEC loss herein matches with results from former investigations where rates between $1.2 \%$ and $19.2 \%$ in the short and long terms were reported, depending on surgical techniques and different OVDs that were used for IOL implantation..$^{20,23,25-33}$ A meta-analysis of different OVDs to protect the CEC during phacoemulsifications was recently published and demonstrated that different OVDs show a 


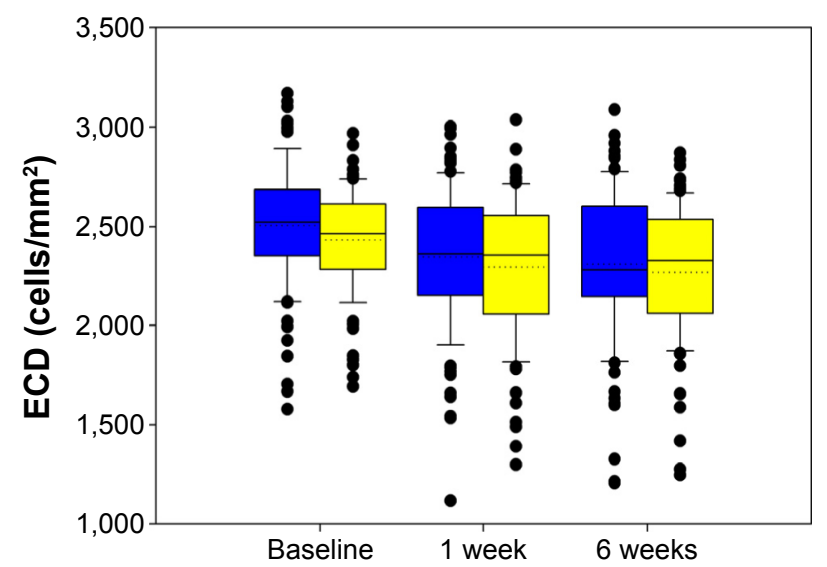

Figure I Comparison of endothelium cell density in both groups. Note: BSS plus ${ }^{\circledR}$ group (blue); Z-Celcoat ${ }^{\mathrm{TM}}$ group (yellow). Abbreviation: ECD, endothelium cell density.

variable impact on CEC loss but that all substances provided a basic CEC protection because CEC loss with each OVD was $<100$ cells/mm after 3 months. ${ }^{10}$ In contrast, comparative studies between BSS only and OVDs are rare. Nayak et al found, similar to the results herein, no difference in CEC loss between a BSS and an OVD group. The setting was different though (no OVD during capsulorhexis, use of a higher viscous OVD). In both groups, postoperative CEC loss was $7.5 \% .{ }^{34}$ Lee et al's study design has more similarities to our setting, but they compared the high viscosity OVD Amvisc Plus $^{\mathrm{TM}}$ (Bausch \& Lomb Incorporated, Bridgewater, NJ, USA) with BSS during hydrophilic acrylic IOL implantation and found a decrease of $\sim 3 \%$ after 3 months without significant differences between both groups. ${ }^{16}$

BCVA increased significantly in both groups after 1 and 6 weeks, and while there were no significant differences at baseline and after 6 weeks, patients assigned to the BSS plus group had a significant better BCVA after 1 week (Table 3 ).

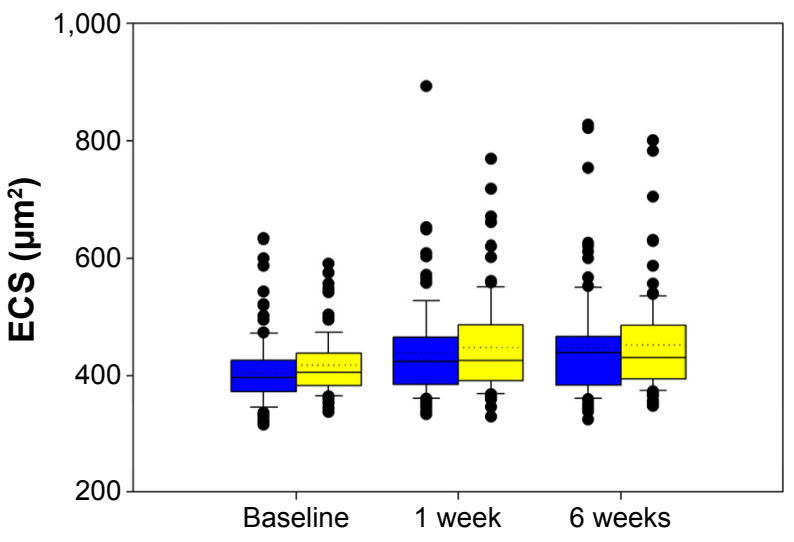

Figure 2 Comparison of endothelium cell size in both groups. Note: BSS plus ${ }^{\circledR}$ group (blue); Z-Celcoat ${ }^{\mathrm{TM}}$ group (yellow).

Abbreviation: ECS, endothelium cell size.

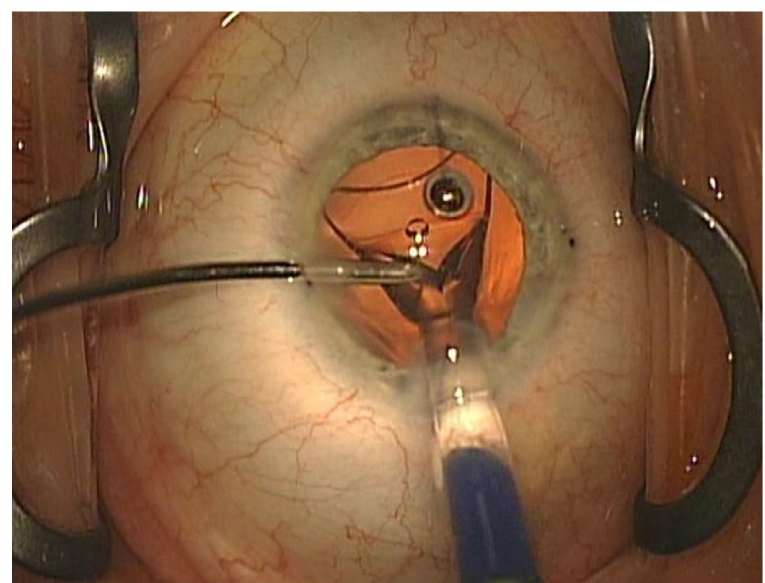

Figure 3 Implantation of an acrylic single-piece intraocular lens using balanced salt solution irrigation only.

By speculation, this difference might be attributed to an overall higher surgical manipulation in eyes assigned to the Z-Celcoat group because overall operation time and notably irrigation-aspiration suction time were significantly longer, which in turn might have strongly impacted CEC function.

IOP levels at baseline and IOP differences after 1 day as well as after 1 and 6 weeks were not different between both groups, although mean IOP showed significant differences on each visit after surgery. While IOP decreased between each postsurgical visit in the BSS plus group, it peaked 1 day after surgery in the Z-Celcoat group reaching presurgical levels in the further course. These differences seem to be neglectable as they were all within normal limits and differences were minor (Table 3). Nevertheless, IOP was lower in eyes assigned to BSS plus group, being suggestive of possible IOP elevations in the Z-Celcoat group. IOP spikes after intraocular use of OVDs during phacoemulsifications have previously been described and typically occur within the first 24 hours after surgery if the OVD is not completely removed. ${ }^{3,8,11,16}$ This highlights the need to evaluate complete OVD removal times. The data herein demonstrate that irrigation-aspiration suction time in the Z-Celcoat group was $20 \%$ and thus significantly longer than in the BSS plus group (Table 3). Furthermore, as all other intraoperative parameters were not different between both groups, the prolonged irrigation-aspiration suction time accounts for an overall significant longer duration of surgery in the Z-Celcoat group of almost 1 minute and thus of $11 \%$. These results are in accordance with former evaluations of OVD removal times. ${ }^{11,12,35} \mathrm{Z}$-Celcoat is a dispersive OVD, and complete removal time differs in comparison to other, for example, cohesive OVDs. ${ }^{11,12,35}$ The effect of the use and especially of the different removal times of various OVDs 
with respect to CEC protection in combination with modern IOLs merits further evaluation because former publications report increased side effects and complications with increasing operation time. ${ }^{3}$ Furthermore, time-sparing approaches increase efficiency and reduce overall costs particularly in high-volume surgical centers. ${ }^{8}$

The mechanical stress of anterior segment tissues during IOL implantation causes a release of different inflammation mediators that in the further course might induce the formation of a cystoid pseudophakic macular edema (Irvine-Gass syndrome) in the posterior part of the eye. ${ }^{36}$ Different OVDs can capture these mediators, and further studies have to evaluate if the rate of eyes developing Irvine-Gass syndrome differ depending on the use of BSS or an OVD during IOL implantation. At least one former publication reported a significant impact of different OVDs on foveal thickness after phacoemulsification and IOL implantation. ${ }^{29}$

\section{Conclusion}

In summary, the results herein indicate that an experienced surgeon does not produce a significant higher decrease of CECs irrespective of the fact whether BSS or OVDs were used during the implantation of an acrylic hydrophilic IOL with a hydrophobic surface coating. IOL implantation using a BSS infusion line seems to be a useful alternative in uncomplicated cataract procedures leading to significant shorter operation times and lesser immediate postoperative IOP increase. Both aspects in turn are of benefit for both patients and cataract surgeons alike. These results should be confirmed in a single-blind and randomized clinical trial with an extended postoperative period such as of 3 months or 6 months.

\section{Acknowledgments}

This manuscript is based on the doctoral thesis of I Manojlovic, Philipps-University of Marburg, 2015. Presented in parts at the Annual Meeting of the German Ophthalmological Society (DOG), October 2014, and the Annual Meeting of the German-Speaking Society of Intraocular Lens Implantation and Refractive Surgery (DGII), February 2014.

\section{Disclosure}

Thomas Bertelmann is a Medical Advisor at Novartis Pharma GmbH, Nuremberg, Germany, and scientific staff of Philipps-University Marburg, Germany. All other authors certify that they have no affiliations with or involvement in any organization or entity with any financial interest (such as honoraria; educational grants; participation in speakers' bureaus; membership, employment, consultancies, stock ownership, or other equity interest; and expert testimony or patent-licensing arrangements) or nonfinancial interest (such as personal or professional relationships, affiliations, knowledge or beliefs) in the subject matter or materials discussed in this manuscript. The authors report no other conflicts of interest in this work.

\section{References}

1. Erie JC. Rising cataract surgery rates: demand and supply. Ophthalmology. 2014;121(1):2-4.

2. Asbell PA, Dualan I, Mindel J, Brocks D, Ahmad M, Epstein S. Agerelated cataract. Lancet. 2005;365(9459):599-609.

3. Bissen-Miyajima H. Ophthalmic viscosurgical devices. Curr Opin Ophthalmol. 2008;19(1):50-54.

4. Schulze S, Bertelmann T, Sekundo W. [Implantation of intraocular lenses in the ciliary sulcus]. Ophthalmologe. 2014;111(4):305-309.

5. Rosado-Adames N, Afshari NA. The changing fate of the corneal endothelium in cataract surgery. Curr Opin Ophthalmol. 2012; 23(1):3-6.

6. Augustin AJ, Dick HB. Oxidative tissue damage after phacoemulsification: influence of ophthalmic viscosurgical devices. J Cataract Refract Surg. 2004;30(2):424-427.

7. Yamazoe K, Yamaguchi T, Hotta K, et al. Outcomes of cataract surgery in eyes with a low corneal endothelial cell density. $J$ Cataract Refract Surg. 2011;37(12):2130-2136.

8. Shingleton BJ, Mitrev PV. Anterior chamber maintainer versus viscoelastic material for intraocular lens implantation: case-control study. $J$ Cataract Refract Surg. 2001;27(5):711-714.

9. Ravalico G, Botteri E, Baccara F. Long-term endothelial changes after implantation of anterior chamber intraocular lenses in cataract surgery. J Cataract Refract Surg. 2003;29(10):1918-1923.

10. Van den Bruel A, Gailly J, Devriese S, Welton NJ, Shortt AJ, Vrijens F. The protective effect of ophthalmic viscoelastic devices on endothelial cell loss during cataract surgery: a meta-analysis using mixed treatment comparisons. Br J Ophthalmol. 2011;95(1):5-10.

11. Bissen-Miyajima H. In vitro behavior of ophthalmic viscosurgical devices during phacoemulsification. J Cataract Refract Surg. 2006; 32(6):1026-1031.

12. Auffarth GU, Holzer MP, Visessook N, Apple DJ, Völcker HE. Removal times for a dispersive and a cohesive ophthalmic viscosurgical device correlated with intraocular lens material. J Cataract Refract Surg. 2004; 30(11):2410-2414.

13. Tu KL, Gaskell A. Capsular bag distension syndrome. Br J Ophthalmol. 1997;81(7):610.

14. Mahdy MA, Eid MZ, Mohammed MA, Hafez A, Bhatia J. Relationship between endothelial cell loss and microcoaxial phacoemulsification parameters in noncomplicated cataract surgery. Clin Ophthalmol. 2012; 6:503-510.

15. Matsuda M, Kinoshita S, Ohashi Y, et al. Comparison of the effects of intraocular irrigating solutions on the corneal endothelium in intraocular lens implantation. Br J Ophthalmol. 1991;75(8):476-479.

16. Lee HY, Choy YJ, Park JS. Comparison of OVD and BSS for maintaining the anterior chamber during IOL implantation. Korean J Ophthalmol. 2011;25(1):15-21.

17. Joussen AM, Barth U, Cubuk H, Koch H. Effect of irrigating solution and irrigation temperature on the cornea and pupil during phacoemulsification. J Cataract Refract Surg. 2000;26(3):392-397.

18. Cameron MD, Poyer JF, Aust SD. Identification of free radicals produced during phacoemulsification. J Cataract Refract Surg. 2001;27(3): 463-470.

19. Skiadaresi E, McAlinden C, Pesudovs K, Polizzi S, Khadka J, Ravalico G. Subjective quality of vision before and after cataract surgery. Arch Ophthalmol. 2012;130(11):1377-1382. 
20. Dick HB, Kohnen T, Jacobi FK, Jacobi KW. Long-term endothelial cell loss following phacoemulsification through a temporal clear corneal incision. J Cataract Refract Surg. 1996;22(1):63-71.

21. Pirazzoli G, D’Eliseo D, Ziosi M, Acciarri R. Effects of phacoemulsification time on the corneal endothelium using phacofracture and phaco chop techniques. J Cataract Refract Surg. 1996;22(7):967-969.

22. Kim DH, Wee WR, Lee JH, Kim MK. The comparison between torsional and conventional mode phacoemulsification in moderate and hard cataracts. Korean J Ophthalmol. 2010;24(6):336-340.

23. Hayashi K, Hayashi H, Nakao F, Hayashi F. Risk factors for corneal endothelial injury during phacoemulsification. J Cataract Refract Surg. 1996;22(8):1079-1084.

24. Hayashi K, Nakao F, Hayashi F. Corneal endothelial cell loss after phacoemulsification using nuclear cracking procedures. J Cataract Refract Surg. 1994;20(1):44-47.

25. Walkow T, Anders N, Klebe S. Endothelial cell loss after phacoemulsification: relation to preoperative and intraoperative parameters. $J$ Cataract Refract Surg. 2000;26(5):727-732.

26. Chylack LT Jr, Wolfe JK, Singer DM, et al. The lens opacities classification system III. The Longitudinal Study of Cataract Study Group. Arch Ophthalmol. 1993;111(6):831-836.

27. Gogate P, Ambardekar P, Kulkarni S, Deshpande R, Joshi S, Deshpande M. Comparison of endothelial cell loss after cataract surgery: phacoemulsification versus manual small-incision cataract surgery: six-week results of a randomized control trial. J Cataract Refract Surg. 2010;36(2):247-253.

28. Bourne RR, Minassian DC, Dart JK, Rosen P, Kaushal S, Wingate N. Effect of cataract surgery on the corneal endothelium: modern phacoemulsification compared with extracapsular cataract surgery. Ophthalmology. 2004;111(4):679-685.
29. Moschos MM, Chatziralli IP, Sergentanis TN. Viscoat versus Visthesia during phacoemulsification cataract surgery: corneal and foveal changes. BMC Ophthalmol. 2011;11:9.

30. Storr-Paulsen A, Nørregaard JC, Farik G, Tårnhøj J. The influence of viscoelastic substances on the corneal endothelial cell population during cataract surgery: a prospective study of cohesive and dispersive viscoelastics. Acta Ophthalmol Scand. 2007;85(2):183-187.

31. Storr-Paulsen A, Norregaard JC, Ahmed S, Storr-Paulsen T, Pedersen TH. Endothelial cell damage after cataract surgery: divide-andconquer versus phaco-chop technique. J Cataract Refract Surg. 2008; 34(6):996-1000.

32. Faramarzi A, Javadi MA, Karimian F, et al. Corneal endothelial cell loss during phacoemulsification: bevel-up versus bevel-down phaco tip. J Cataract Refract Surg. 2011;37(11):1971-1976.

33. Mathew PT, David S, Thomas N. Endothelial cell loss and central corneal thickness in patients with and without diabetes after manual small incision cataract surgery. Cornea. 2011;30(4):424-428.

34. Nayak BK, Jain EK. Comparison of corneal endothelial cell loss during phacoemulsification using continuous anterior chamber infusion versus those using ophthalmic viscosurgical device: randomized controlled trial. Indian J Ophthalmol. 2009;57(2):99-103.

35. Petroll WM, Jafari M, Lane SS, Jester JV, Cavanagh HD. Quantitative assessment of ophthalmic viscosurgical device retention using in vivo confocal microscopy. J Cataract Refract Surg. 2005;31(12): 2363-2368.

36. Bertelmann T, Witteborn M, Mennel S. [Pseudophakic cystoid macular oedema]. Klin Monbl Augenheilkd. 2012;229(8):798-811.
Clinical Ophthalmology

\section{Publish your work in this journal}

Clinical Ophthalmology is an international, peer-reviewed journal covering all subspecialties within ophthalmology. Key topics include: Optometry; Visual science; Pharmacology and drug therapy in eye diseases; Basic Sciences; Primary and Secondary eye care; Patient Safety and Quality of Care Improvements. This journal is indexed on

\footnotetext{
Submit your manuscript here: http://www.dovepress.com/clinical-ophthalmology-journal
}

\section{Dovepress}

PubMed Central and CAS, and is the official journal of The Society of Clinical Ophthalmology (SCO). The manuscript management system is completely online and includes a very quick and fair peer-review system, which is all easy to use. Visit http://www.dovepress.com/ testimonials.php to read real quotes from published authors. 